\title{
Modeling of long-range transport on Taiwan's acid deposition under different weather conditions
}

\author{
Ken-Hui Chang ${ }^{\mathrm{a}, *}$, Fu-Tien Jeng ${ }^{\mathrm{b}}$, Ya-Ling Tsai ${ }^{\mathrm{b}}$, Pay-Liam Lin ${ }^{\mathrm{c}}$ \\ ${ }^{a}$ Department of Environmental and Safety Engineering, National Yunlin University of Science and Technology, Taiwan \\ ${ }^{\mathrm{b}}$ Graduate Institute of Environmental Engineering, National Taiwan University, Taiwan \\ ${ }^{\mathrm{c}}$ Department of Atmospheric Science, National Central University, Taiwan
}

Received 23 February 1999; received in revised form 16 November 1999; accepted 1 December 1999

\begin{abstract}
The long-range and transboundary transport of acid deposition precursors in East Asia has become an important issue due to the industrial development in this area in recent years. To represent an entire year's impact by long-range transport for Taiwan's acid deposition, six episodes in 1993 were selected for study using Taiwan Air Quality Model, which was developed on the basis of the Regional Acid Deposition Model system. The six episodes cover five types of weather conditions including the Northeasterly monsoon, Spring stationary front, Mei-Yu front, Summer shower, and Autumn front. Two emission conditions were simulated for each episode to quantify the long-range transport effect. One condition takes all emissions within the simulated domain into account as a base case, while another condition excludes Taiwan's emission and considers all of the other emissions as a control case. The results of the present study indicate that contributions of long-range transport to Taiwan's sulfur depositions range from 9 to $45 \%$ and nitrogen depositions from 6 to $33 \%$ for the six episodes. The most serious effect of long-range transport is the northeasterly monsoon episode for both total sulfur and total nitrogen deposition. The entire year contribution by long-range transport is estimated to be $39 \%$ for wet sulfate deposition, and 37\% for wet nitrogen deposition for Taiwan. (C) 2000 Elsevier Science Ltd. All rights reserved.
\end{abstract}

Keywords: Air quality model; Transboundary transport; Impact ratio; Sulfur deposition; Nitrogen deposition

\section{Introduction}

Routine acid deposition monitoring in Taiwan has been conducted since 1990. Currently there are 12 monitoring stations. The $\mathrm{pH}$ values in the past years ranged from 4.21 to 5.34 for all sites with the lowest values in northern Taiwan in the wintertime. However, the prevailing winds in northern Taiwan are northeasterly during the wintertime and its upstream area has very few emission sources. Thus, acid deposition prob-

\footnotetext{
* Corresponding author. Tel.: + 886-5-5342601 ext. 4417; fax: + 886-5-5312069.

E-mail address: ken@airlab.yuntech.edu.tw (K.-H. Chang).
}

ably is affected by long-range transboundary transport. In fact, Wu et al. (1991) found that the major source of long-range transport (LRT) affecting Taiwan air quality in a typical northeasterly monsoon period was from Shanghai area of Mainland China. Kitada et al. (1992) also report that a significant ratio $(30-40 \%)$ of the sulfate present in high acidic precipitation in winter in the western coastal area of Japan comes from Mainland China. Ichikawa and Fujita (1995) have further estimated that Mainland China is a major source of wet sulfate deposition in Japan and it contributes about 50\% of Japan's overall anthropogenic deposition. In contrast, Huang et al. (1995) estimate that Mainland China contributes only $3.5 \%$ of Japan's total sulfur deposition based on higher wet $\mathrm{SO}_{2}$ and sulfate removal rates. Highly parameterized representations of wet and dry removal rates are usually 
fit to the limited data observed under particular areas and weather conditions. Whether these empirical parameters are applicable to other substantially different environments is difficult to assess.

The problems of acid deposition result from a complex series of interactions among atmospheric chemical species that are emitted from both anthropogenic and natural sources. Some of these compounds are subsequently oxidized into more acidic forms through a complicated series of chemical, meteorological and physical interactions, while others are neutralized or unchanged. Considering the uncertainty of simple empirical relationships derived from limited data and trajectory model with highly parameterized deposition rates for acid deposition, it might be useful to use an integrated theoretical modeling system that includes the relevant physical and chemical phenomena for studying the LRT problem. Taiwan Air Quality Model (TAQM), starting with Regional Acid Deposition Model (RADM) (Chang et al., 1987; Chang, 1990), has been established with a preliminary validation (Chang and Jeng, 1995). Consequently, the TAQM with some modifications will be used in the present study to simulate the acid deposition in East Asia. Because the transport and precipitation patterns in East Asia show significant variations throughout the year (Arndt et al., 1998), six episodes covering different weather types will be modeled to capture the entire year's picture. The results should enhance a better understanding of the role of LRT of pollutants in Taiwan's air quality.

\section{Description of TAQM}

The TAQM was developed for modeling the air quality and acidic deposition in Taiwan. Initially, TAQM was an extension and adaptation of the existing RADM version 2 (RADM2) (Chang et al., 1987; Chang, 1990), developed for the USEPA under the National Acid Precipitation and Assessment Program. With further modifications, TAQM allows the use of nonhydrostatic meteorological data, generated by the Penn State/NCAR Mesoscale Model, version 5 (MM5) (Grell et al., 1993). This allows the model to have a much wider applicability, rather than limited to the condition of hydrostatic balance in the meteorological data. Atmospheric transport, source emission, dry and wet deposition removal, and chemical transformation govern the air concentration of each atmospheric trace species in the model. TAQM solves a set of chemical species conservation equations

$$
\begin{aligned}
\frac{\partial C}{\partial t}= & -\nabla \cdot(V C)+\nabla \cdot\left(K_{\mathrm{e}} L C\right)+P_{\mathrm{chem}}-L_{\mathrm{chem}} \\
& +E+\left(\frac{\partial C}{\partial t}\right)_{\mathrm{clouds}}+\left(\frac{\partial C}{\partial t}\right)_{\mathrm{dry}},
\end{aligned}
$$

where $C$ is the species volume mixing ratio, $V$ is the three-dimensional velocity vector at each grid point in the model domain, $K_{\mathrm{e}}$ is the eddy diffusivity used to parameterize the subgrid-scale fluxes, $P_{\text {chem }}$ and $L_{\text {chem }}$ are the production and loss rates due to chemical interactions, $E$ is the emission rate, $(\partial C / \partial t)_{\text {clouds }}$ is the time rate of change of concentration due to cloud effects, and $(\partial C / \partial t)_{\text {dry }}$ represents the change in concentration due to dry deposition.

The horizontal coordinate system in the TAQM uses a Lambert conformal projection for the simplicity of numerical implementations and compatibility with MM5. TAQM uses a terrain following non-hydrostatic $\sigma$ coordinate system in the vertical direction. The vertical coordinate $\sigma$ is defined as a function of a selected reference state of the atmosphere (which does not change with time) and has the following form:

$\sigma=\frac{P_{0}-P_{\mathrm{T} 0}}{P_{\mathrm{S} 0}-P_{\mathrm{T} 0}}$

where $P_{\text {To }}$ is the reference pressure at the top of the model and is set to $100 \mathrm{mb}, P_{0}$ is the reference pressure at a given point $(x, y, z)$, and $P_{\mathrm{So}}$ is the reference pressure at the surface at position $(x, y)$. The selected reference state of the atmosphere is established according to hydrostatic balance (Dudhia, 1993):

$\frac{\partial P_{0}}{\partial z}=-\rho_{0} g$

and

$T_{0}=T_{\mathrm{S} 0}+A \ln \left(\frac{P_{0}}{P_{00}}\right)$,

where $T_{\text {so }}=280 \mathrm{~K}, A=50 \mathrm{~K}$ and $P_{00}=1000 \mathrm{mb}$.

The vertical eddy diffusion calculation is based on $K$-theory for non-convective atmospheric conditions as described in Chang et al. (1987). Under convective conditions, a non-local closure asymmetrical mixing scheme developed by Pleim and Chang (1992) is implemented.

Chemical reactions involving the oxidation of organic compounds and $\mathrm{NO}_{x}$ are most important to the formation of ozone. The gas phase chemical mechanisms of the TAQM employ the RADM2 approach (transformation of 63 species in 158 reactions) developed by Stockwell et al. (1990). The inorganic chemistry reaction consists of 14 stable, 4 intermediate and 3 abundant stable species, whereas the organic chemistry is represented by 26 stable species and 16 peroxy radicals. The stable organic species include 5 alkanes (methane, ethane, and 3 higher lumped groups), 4 alkenes (ethene, terminal and internal alkenes, and isoprene), 3 aromatics (toluene, xylene, and cresol), 6 carbonyls (aldehydes, ketones, and dicarbonyls), 3 organic peroxides, 2 organic acids (formic and acetic acid), 2 organic nitrates, and peroxyacyl nitrate (PAN). Clear sky photolysis rates are calculated as a function of daytime, latitude and height. Photolysis rates are 
enhanced above clouds and are reduced below clouds sometimes to near zero values (Madronich, 1987).

The rate of change of atmospheric trace gases due to dry deposition is commonly simulated in terms of dry deposition velocity (Chang et al., 1987). The dry deposition fluxes are determined from deposition velocities and the species concentrations in the model surface layer. A series resistance modeling approach is employed to account for deposition velocity in the TAQM. Clouds play an important role in the vertical redistribution, chemical transformation, and removal of trace species in the troposphere. It is computationally impractical to calculate explicitly the effects of both cloud- and regional-scale phenomena in the framework of a regional model, and thus these effects are parameterized. The parameterization method in the TAQM is described elsewhere (Walcek and Taylor, 1986; Chang et al., 1987). Changes in trace species concentration due to rainout or chemical reactions of soluble and reactive gases in a cloud are computed using a box aqueous chemical model. Cloudwater composition is computed using a hybrid equilibrium and kinetic chemical model, and the $\mathrm{pH}$ is determined by solving an ion balance as described in Walcek and Taylor (1986).

A set of partial differential equations of mass conservation for the species in atmosphere is solved numerically with finite difference approximations. Because of the unique mathematical characteristics of the principal components of Eq. (1), the operator splitting technique is used to optimize the accuracy of the overall solution technique and the operational efficiency of the model. TAQM uses a positive definite and mass conservative fourth-order finite difference scheme for the two horizontal one-dimensional advection operators (Bott, 1989a, b). In the vertical section, a new second-order scheme with non-uniform grid sizes of Bott's type has been derived and applied. The standard second-order Crank-Nicolson implicit scheme is applied to each of the 1-D diffusion equation in flux conservative form taking into account the non-uniform grids in the vertical direction. The gasphase photochemical reactions form a well-known stiff system of differential equations. TAQM uses the RADM chemistry solver (Chang et al., 1987) which is about five times faster than Gear solver (Gear, 1971) if operator splitting is imposed. The solver divides all the chemical species into four classes: families of closely interacting species, short-lived species (mostly radicals and intermediates), long-lived species, and a special radical grouping of $\mathrm{HO}$ and $\mathrm{HO}_{2}$. Different solution techniques are used for each of these classes.

\section{Approach}

Long term simulation can be implemented to obtain annual acid deposition patterns using either a trajectory model (Arndt et al., 1998) or a hybrid model, which employs a trajectory model for far sources and Eulerian model for nearby sources (Hayami and Ichikawa, 1995; Ichikawa and Fujita, 1995). For a comprehensive Eulerian model such as TAQM, long term simulation is usually not applicable with limited computation resources and inconvenience to analyze the model results. The typical simulation period for this type of model is $3-5 \mathrm{~d}$, which can generally cover a major acid deposition episode. Depending on the weather type, the source-receptor relationship for acidic deposition can be different. In order to obtain a better understanding of such relationships and to accommodate the restrictions, it is necessary to select representative episodes for the present model study.

The domain in this study is divided into $64 \times 60$ uniform grids horizontally with a $60 \mathrm{~km} \times 60 \mathrm{~km}$ resolution. It covers Taiwan, South and North Korea, a major part of Mainland China and Japan, as well as part of the Philippine.

\subsection{Description of selected episodes}

To represent annual influence of LRT on Taiwan's acid deposition, six episodes in 1993 were selected for study. Because the northeasterly monsoon season can extend almost six months (October to March), two monsoon episodes during the season were selected. The periods of six episodes that cover 5 types of weather conditions are described below:

Episode 1: Northeasterly monsoon I (NM1): 00Z, 15 January - 00Z, 19 January 1993. A continental cold highpressure $(1037 \mathrm{hPa})$ formed on 14 January 1993 and moved to southeast during the next few days. Severe cold air with strong northeasterly wind advanced to Taiwan Area due to the strong pressure gradient accompanied with the combination of the Siberian high pressure and Aluetian low-pressure system. Wild-spread cloud band expanded from east of Japan to southeast Mainland China, and the front system brought Taiwan precipitation all over the island during this episode. This is the typical weather system (the so-called Asian cold surge) that occurs occasionally in the East Asian winter. This cold surge decayed on January 18 due to the weakened continental cold high pressure by the modification of the moving fraction and warm boundary; it then disappeared on January 19. The model results of accumulative precipitation and average wind field at sixth layer ( $\sim 850$ mbar) during the episode are shown in Fig. 1.

Episode 2: Spring stationary front (SSF): 00Z, 14 April-00Z, 19 April 1993. In spring, continental cold high pressure system is weakened but it still controls the weather of East Asia. This episode occurred on 12 April 1993; there was a stationary front formed among the sea-modified high pressure, cold continental high pressure and the Pacific high pressure. It lasted for $6 \mathrm{~d}$ over the coastline of East Asia, and rainfall reported by all the 

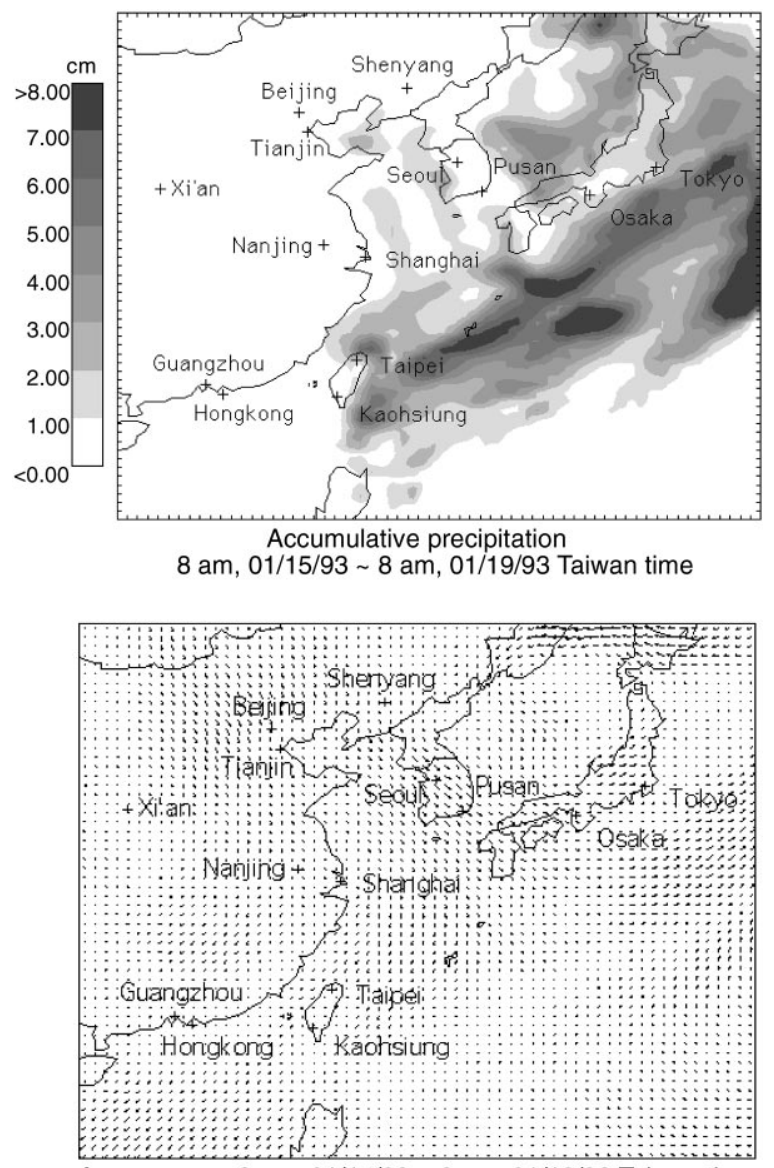

Average over 8 am, 01/15/93 8 am, 01/19/93 Taiwan time Winds at $Z=6, \operatorname{Max}=17.9 \mathrm{~m} / \mathrm{s}$ at $(46,58)=-$

Fig. 1. Spatial distribution of accumulative precipitation (upper) and average wind field (lower) during the period of northeasterly monsoon (I) episode.

surface observation stations of Taiwan Island. On 19 April, the continental high pressure moved to East Sea and pushed the front passed over Taiwan and ended the episode.

Episode 3: Mei-Yu front (MYF): 00Z, 27 May-00Z, 31 May 1993. During May and June the long-lived stationary front usually occupies Taiwan Area. These weather system, affecting Taiwan area at this period, is the so-called Mei-Yu front. While these fronts move from southwestern China to Taiwan, it could bring abundant rainfall and triggers flash flooding episodes. In this event, a Mei-Yu front located on the East Asia from southeast Japan passed through Taiwan and extended to the south mainland China. The cloudy, rainy weather lasted for $5 \mathrm{~d}$ but changed on 31 May since the sub tropical Pacific high-pressure moved to the northwest.

Episode 4: Summer shower (SS): 00Z, 25 June-00Z, 29 June 1993. Local shower usually occurs in summer warm season in Taiwan due to the presence of the orographic warm and moist cloud. On 24 June 1993, Typhoon Coryn moved from Philippine to Hong-Kong and the surrounding typhoon circulation advected the unstable air mass to Taiwan. Local circulation due to warm terrain surroundings played a significant effect on the local precipitation until the Coryn was far away from Taiwan on 29 June.

Episode 5: Autumn front (AF): 00Z, 30 September-00Z, 3 October 1993. A low-pressure moved from southern Mainland China to the northeast of Taiwan island and connected with the Japan low pressure to form an expanded front system in East Asia. This autumn seasonal front passed through Taiwan Area in a short time and then the post-front wide-spread cloud system affected Taiwan for a few days. During front passage, precipitation was obstructed by the high mountain terrain (Central Mountain Range) in Taiwan; hence, no rain found in the southern part of Taiwan. But in the post-front period, the strong stratiform cloud rained all over the island.

Episode 6: Northeasterly monsoon II (NM2): 00Z, 13 December-00Z, 17 December 1993. The northeasterly monsoon dominates the winter weather of Taiwan. Strong northeasterly cold front causes low temperature and rainfall at that time. A continental high pressure moves from Mainland China to the ocean modified by the warm sea. The front located on the north of Taiwan Strait for a few days then moved eastward since the Pacific high pressure was weakened. This typical winter weather system obviously made long-lasting northeasterly wind over Taiwan Area. The wind speed observed in this episode, however, is much weaker than episode 1, and the pollution is not as serious as in episode 1 .

\subsection{Base and control case}

In order to quantify the impact of transboundary and LRT on Taiwan's acid deposition, two different emission conditions, treated as TAQM input, are simulated separately using the same meteorological data for each episode. One condition considers all emissions in Taiwan and other countries in East Asia, called base case, while control case considers all emissions in the countries in East Asia except for Taiwan. Because Taiwan is assumed without discharging any emission in the control case, the acid deposition spreaded over Taiwan would have been transported from other countries and could be counted as the contribution of LRT. Moreover, the ratio of the deposition amount in the control case to that in the base case can be expressed as an impact ratio of the LRT.

\section{Emission data}

Emission data for Taiwan were obtained from Taiwan Emission Data System (CTCI, 1995). The database 
proposed by Akimoto and Narita (1994) was adopted for countries in East Asia except for Taiwan.

\subsection{Taiwan emission data}

The 1993 database is adopted in this study to be consistent with selected episodes. Three categories of point, line, and area sources are included in the database with spatial resolution of $1 \mathrm{~km}$ by $1 \mathrm{~km}$. Pollutants in the database include $\mathrm{SO}_{x}, \mathrm{NO}_{x}, \mathrm{TSP}, \mathrm{PM}_{10}, \mathrm{CO}$, THC (total hydrocarbon), and $\mathrm{Pb}$. The emission amounts for each type of source are estimated using the emission factor method. Each point source in the database contains information for annual emission rate, stack characteristics, fuel type, operating duration, and process code, among others. Since the data resolution is finer than that of the model domain in this study, all of the emission records are processed and allocated into suitable grid cells in the model domain. The estimates of Taiwan emission for $\mathrm{SO}_{x}, \mathrm{NO}_{x}$ and $\mathrm{THC}$ are presented in Table 1.

\subsection{Asia emission data}

The emission database of Akimoto and Narita (1994), without classification by source type, includes three pollutants $\left(\mathrm{SO}_{x}, \mathrm{NO}_{x}\right.$ and $\left.\mathrm{CO}_{2}\right)$ with $1^{\circ}$ longitude by $1^{\circ}$ latitude resolution. The emission amounts are estimated on the basis of the individual fuel consumption and metal production in each economic sector for each country/region in Asia. The emission data from Akimoto and Narita's database are assumed to be area sources and emitted on the surface. Each $1^{\circ} \times 1^{\circ}$ grid emission amount is divided by different weightings into 25 grids. After this partition step, the data resolution $\left(0.2^{\circ} \times 0.2^{\circ}\right)$ is finer than the model's $60 \mathrm{~km} \times 60 \mathrm{~km}$ resolution; the data can then be allocated into suitable grid cells in the model domain. Note that the emission rate for THC is estimated from the $\mathrm{NO}_{x}$ emission using the ratio of the THC to $\mathrm{NO}_{x}$ emission in Taiwan. To account for the emission data in 1993 from the base-year of 1987, the growth rate of $30 \%$ for Japan and $35 \%$ for other countries including Mainland China for both $\mathrm{SO}_{x}$ and $\mathrm{NO}_{x}$ was used.

\section{Table 1}

Estimates of Taiwan emissions in 1993

\begin{tabular}{llll}
\hline & $\begin{array}{l}\mathrm{SO}_{x} \\
\mathrm{Mg} \mathrm{S} \mathrm{yr}^{-1}(\%)\end{array}$ & $\begin{array}{l}\mathrm{NO}_{x} \\
\mathrm{~g} \mathrm{~N} \mathrm{yr}^{-1}(\%)\end{array}$ & $\begin{array}{l}\mathrm{THC} \\
\mathrm{Mg} \mathrm{yr}^{-1}(\%)\end{array}$ \\
\hline Point source & $256,260(91.5 \%)$ & $109,130(35.2 \%)$ & $148,770(15.9 \%)$ \\
Area source & $5650(2.0 \%)$ & $7380(2.4 \%)$ & $352,120(37.6 \%)$ \\
Line source & $18,150(6.5 \%)$ & $193,420(62.4 \%)$ & $434,580(46.5 \%)$ \\
Total & $280,060(100 \%)$ & $309,930(100 \%)$ & $935,470(100 \%)$ \\
\hline
\end{tabular}

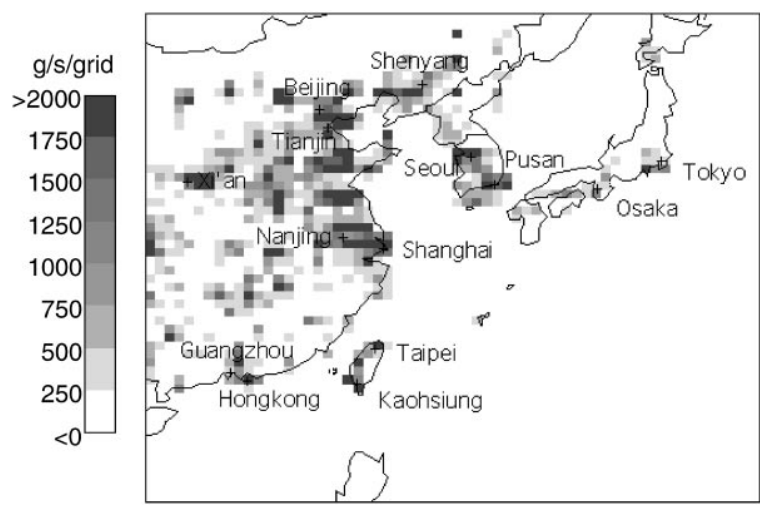

Fig. 2. Spatial distribution of typical $\mathrm{SO}_{x}$ emission in East Asia.

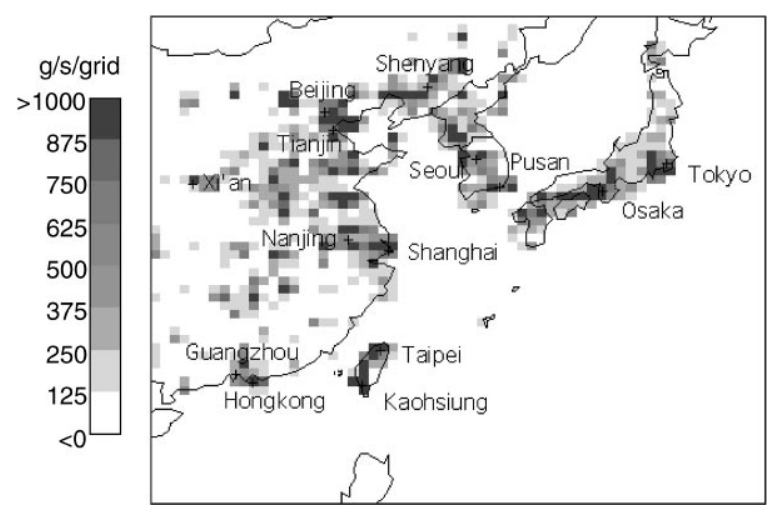

Fig. 3. Spatial distribution of typical $\mathrm{NO}_{x}$ emission in East Asia.

\subsection{Spatial distribution of $\mathrm{SO}_{x}$ and $N O_{x}$ emission}

After the compilation of emission preprocessor, the typical spatial distributions of anthropogenic $\mathrm{SO}_{x}$ and $\mathrm{NO}_{x}$ emissions over the model domain are shown in Figs. 2 and 3, respectively. Taiwan is surrounded by ocean and two-thirds of the surface area is occupied by mountains (up to $300 \mathrm{~m}$ ). There are two major cities in Taiwan. Taipei is a capital city with dense and the largest population, while Kaohsiung is a heavily industrialized city. The major pollutant areas in Taiwan are located in Taipei and Kaohsiung metropolitan areas, e.g., $\mathrm{SO}_{x}$ and $\mathrm{NO}_{x}$ emission intensities are about 1.7 and $0.8 \mathrm{~g} \mathrm{~s}^{-1} \mathrm{~km}^{-2}$, respectively, in Taipei. The largest emission sources of both $\mathrm{SO}_{x}$ and $\mathrm{NO}_{x}$ within the simulated domain are around the Shanghai metropolitan area. The other major source areas for $\mathrm{SO}_{x}$ are Beijing, Nanjing, Tianjing and Guangzhou in mainland China, as well as Seoul and Pusan in South Korea, while those for $\mathrm{NO}_{x}$ are Tokyo and Osaka in Japan, Beijing, Nanjing and Guangzhou in mainland China, Hong Kong, as well as 
Seoul and Pusan in South Korea. Compared to the $\mathrm{NO}_{x}$ emission distribution, $\mathrm{SO}_{x}$ emission is distributed more extensively in Mainland China, with little in Japan.

\section{Results and discussion}

\subsection{Comparison of model results with observations}

The wet deposition was measured with an automatic bucket sampler on a daily basis in 12 monitoring stations so that the model results could be compared with the daily measured data. The scatter plots of model results with observed data for precipitation, sulfate and nitrate are shown in Figs. 4-6, respectively. Only few stations have observation data in the episodes of SSF, SS, and $\mathrm{AF}$. The model tends to underestimate for precipitation, especially in SS and NM2 episodes although the model results are agreeable for the NM1 episode. The model also slightly underestimates sulfate concentration in rainwater. For nitrate concentration in rainwater, however, the model results show no significant bias, but more scattered. Nonetheless, the majority of data are still lying within the error of a factor of 3 for sulfate and nitrate.

The underestimation for sulfate may be due to handling of emission database. Since Akimoto and Narita database used does not classify the emission into point, line, and area sources, all emissions treated as area sources except for Taiwan in this study may not be suitable, especially for $\mathrm{SO}_{x}$. This is because $\mathrm{SO}_{x}$ emission is mostly discharged by stacks from power plants and industrial combustion processes, while $\mathrm{NO}_{x}$ emission is also discharged from vehicles at the ground level in addition to

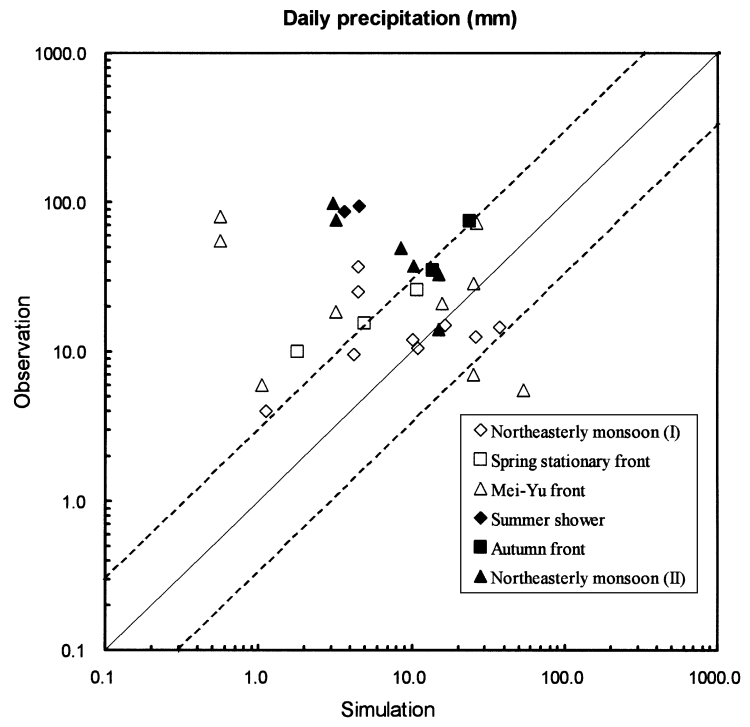

Fig. 4. Comparison between model simulations and observations for daily precipitation $(\mathrm{mm})$ for the six episodes.

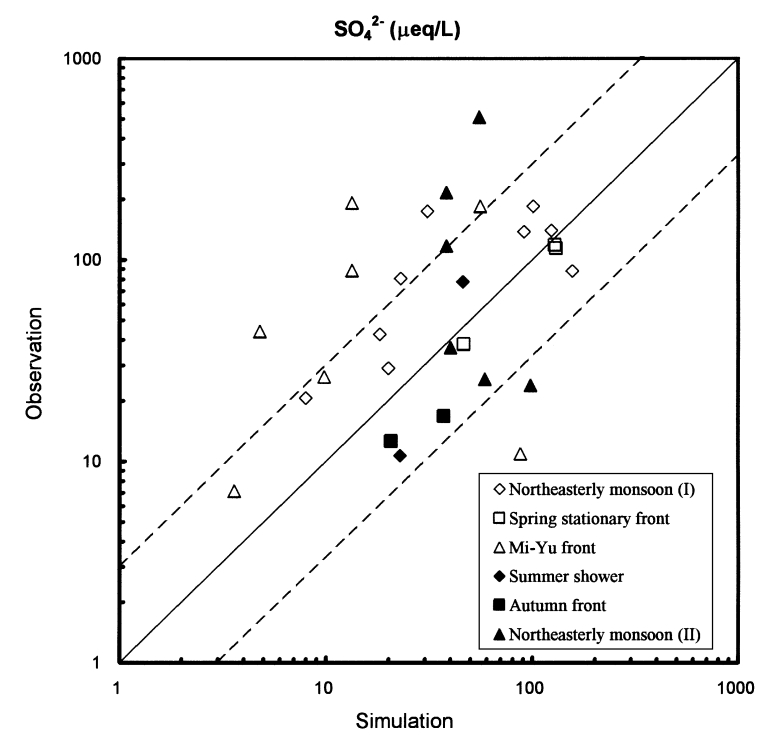

Fig. 5. Comparison between model simulations and observations for wet sulfate concentration $\left(\mu \mathrm{eq} 1^{-1}\right)$ in rain water for the six episodes.

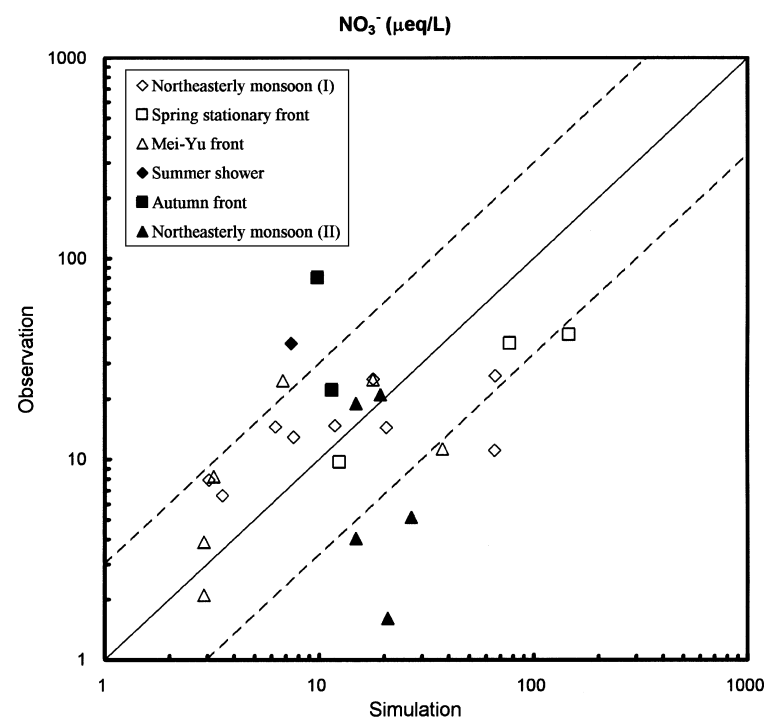

Fig. 6. Comparison between model simulations and observations for wet nitrate concentration $\left(\mu \mathrm{eq} 1^{-1}\right)$ in rain water for the six episodes.

stacks. The emission transported at a higher effective stack height (stack height plus plume rise) should be of more concern for LRT. Also, the relatively high impact ratios of LRT for wet sulfate deposition as compared to that for wet nitrate deposition (first three episodes, Table 2) implies that the contribution of LRT is more important for the wet sulfate deposition than wet nitrate 


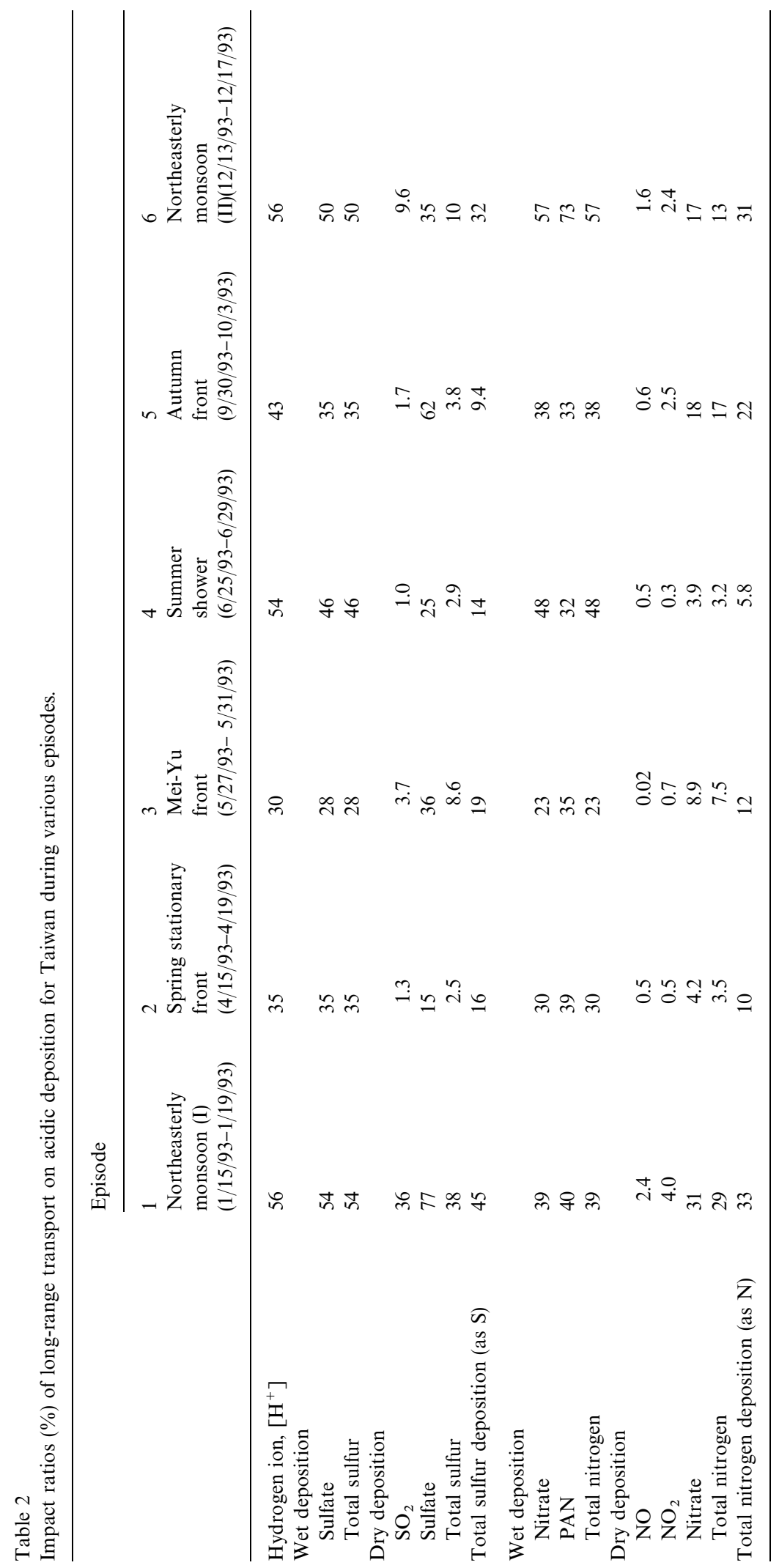




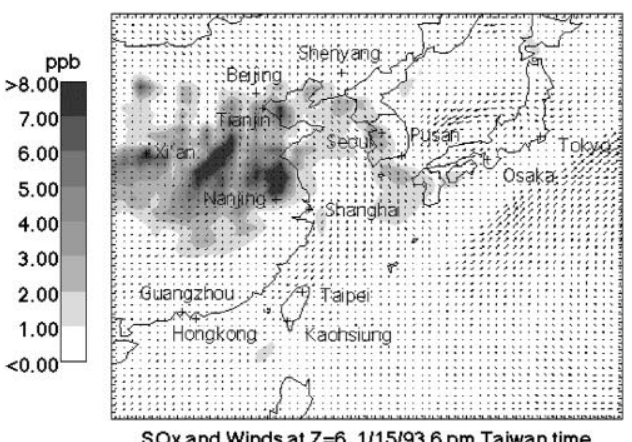

SO $x$ and Winds at $Z=6,1 / 15 / 936 \mathrm{pm}$ Taiwan time Max Wind $=25.6 \mathrm{~m} / \mathrm{s}$ at $(62,40)=-$

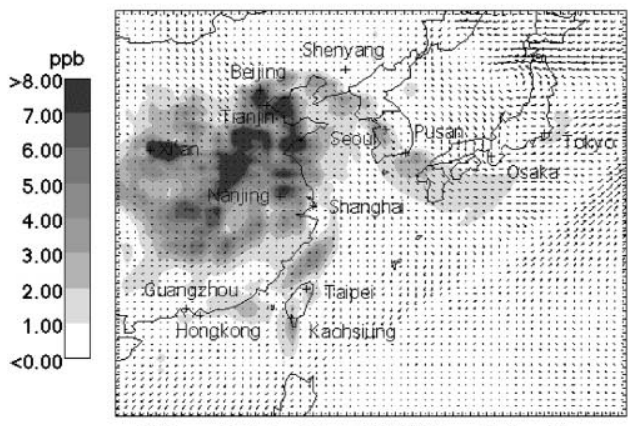

SO $x$ and Winds at $Z=6,1 / 16 / 936 \mathrm{pm}$ Taiwan time Max Wind $=25.2 \mathrm{~m} / \mathrm{s}$ at $(62,36)=-$
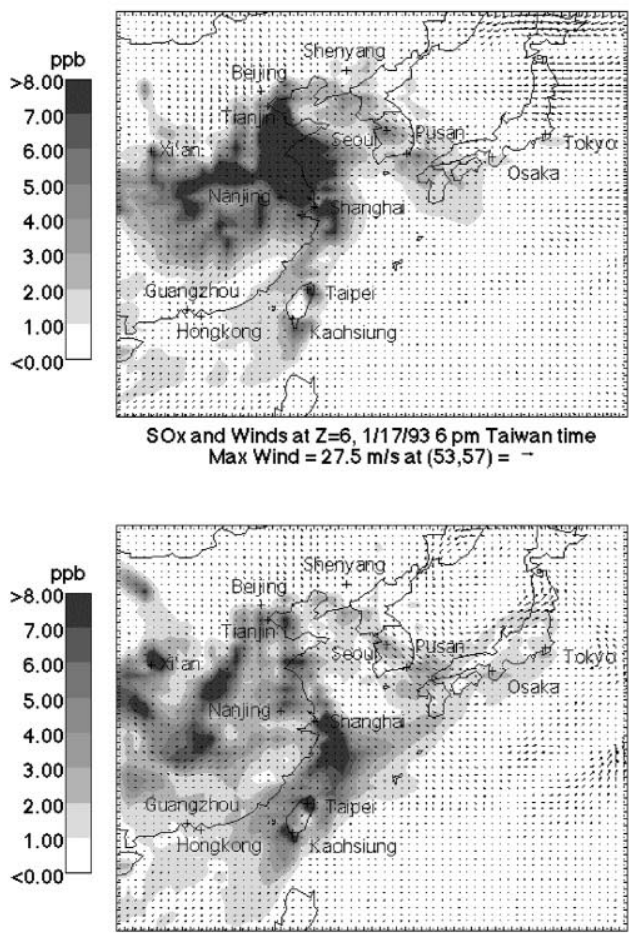

SO $x$ and Winds at $Z=6,1 / 18 / 936 \mathrm{pm}$ Taiwan time Max Wind $=26.8 \mathrm{~m} / \mathrm{s}$ at $(61.25)=\rightarrow$

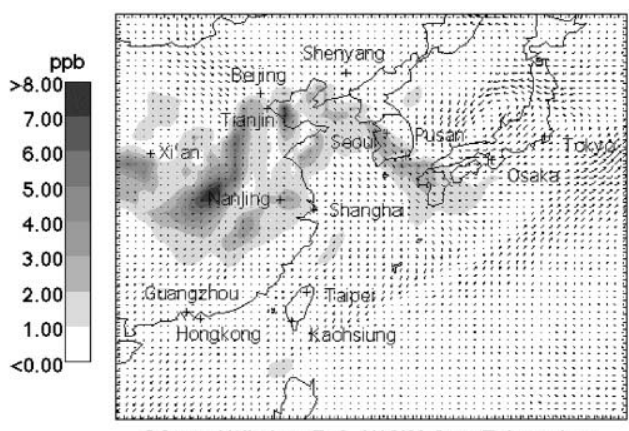

SO $x$ and Winds at $Z=6,1 / 16 / 936$ am Taiwan time Max Wind $=25.8 \mathrm{~m} / \mathrm{s}$ at $(60,38)=-$

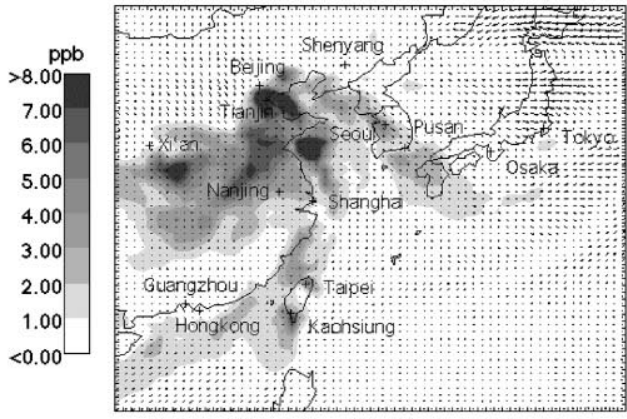

So $x$ and Winds at $Z=6,1 / 17 / 936$ am Taiwan time Max Wind $=27.6 \mathrm{~m} / \mathrm{s}$ at $(53,56)=\rightarrow$

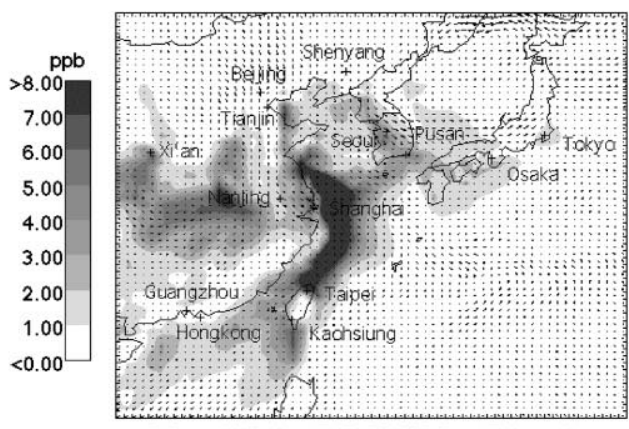

SO $x$ and Winds at $Z=6,1 / 18 / 936$ am Taiwan time Max Wind $=25.4 \mathrm{~m} / \mathrm{s}$ at $(45,57)=-$

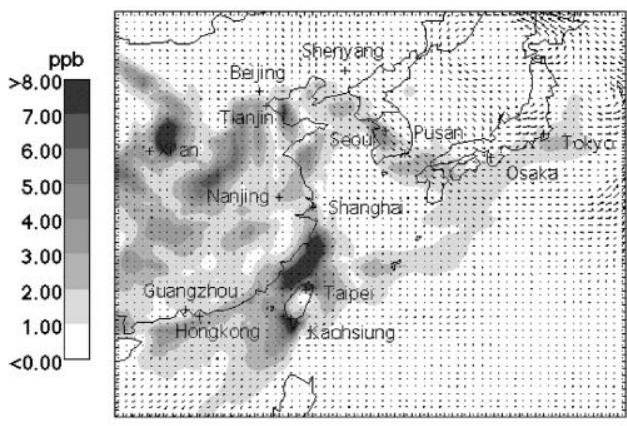

SO $x$ and Winds at $Z=6,1 / 19 / 936$ am Taiwan time Max Wind $=24.6 \mathrm{~m} / \mathrm{s}$ at $(52,57)=\rightarrow$

Fig. 7. Evolution of the $\mathrm{SO}_{x}$ concentration and wind field during the northeasterly monsoon $(\mathrm{I})$ episode at the model sixth level $(\sim 1000$ m). One figure for every $12 \mathrm{~h}$ from $6 \mathrm{pm} \mathrm{1/15/93} \mathrm{to} 6$ am 1/19/93 Taiwan time. 
deposition, even though all the sources of LRT are emitted at the ground level in the model. The dual effect of emission and LRT, therefore, may explain the fact that the degree of underestimation for sulfate is slightly significant than that of nitrate.

\subsection{Effect of LRT in northeasterly monsoon (I) episode}

Because of the seasonal variations in meteorological patterns in East Asia, every country in this region has the potential as being the source of pollutants for other countries during some part of the year. Conversely, each country has the chance of being the receptor of others' pollutants. The northeasterly monsoon (I) episode is chosen to illustrate this phenomenon. This episode is a typical winter outbreak weather, due to southeastward movement of a continental cold airmass from Siberia. Coupling with a low-pressure system near the east of Japan, strong pressure gradients are formed in the sealand adjacencies of East Asia. Northeasterly winds blow directly to Taiwan and bring cold and cloudy weather with precipitation. In the period of this episode from $1 / 14$ 00Z ( 8 am local time) to $1 / 1900 \mathrm{Z}, 1993$, precipitation was observed all over Taiwan, especially in the northern part of Taiwan. The rainwater samples in western Taiwan exhibited higher acidity. Among the monitoring records, the Taipei station located in northwestern Taiwan was observed to have the highest rainwater acidity with a $\mathrm{pH}$ value of 3.5 , while the rainwater acidity in the station located in southeastern Taiwan was close to the natural $\mathrm{pH}$ value of 6.2. The fact that the central mountain ranges in Taiwan exhibit a blocking effect implies that acidic materials may come from Mainland China.

\subsubsection{Evolution of $S O_{x}$ concentration}

The sixth vertical layer of model $(850 \mathrm{mb}$ and $1000 \mathrm{~m}$ above ground level), selected as a target layer, sits around the planetary boundary layer such that the pollutants are moved quickly and not affected by the terrain structure. The $\mathrm{SO}_{x}$ concentration (including $\mathrm{SO}_{2}$ and sulfate in the air) distribution in East Asia is shown every $12 \mathrm{~h}$ for $4 \mathrm{~d}$ in Fig. 7. During the episode of northeasterly monsoon the air stream starting from Mongolia was moving to northeast of China, and then splitting into two streams. One is moving toward east, across Japan, and then toward northeast. Another is moving toward south, and then turning toward southwest around Yellow Sea, along the coast of China to South China Sea. At the first $\mathrm{SO}_{x}$ distribution scenario (6 p.m., 1/15/93), the $\mathrm{SO}_{x}$ concentration is low in Japan and Taiwan. As time progressed, there were significant $\mathrm{SO}_{x}$ pollutant concentrations in the same area. The pollutant front moved from Shanghai area to Taiwan, and to some extent, from Korea and north of China to Japan. The influence of LRT lasted until 1/18/93, in which the $\mathrm{SO}_{x}$ almost covered the entire
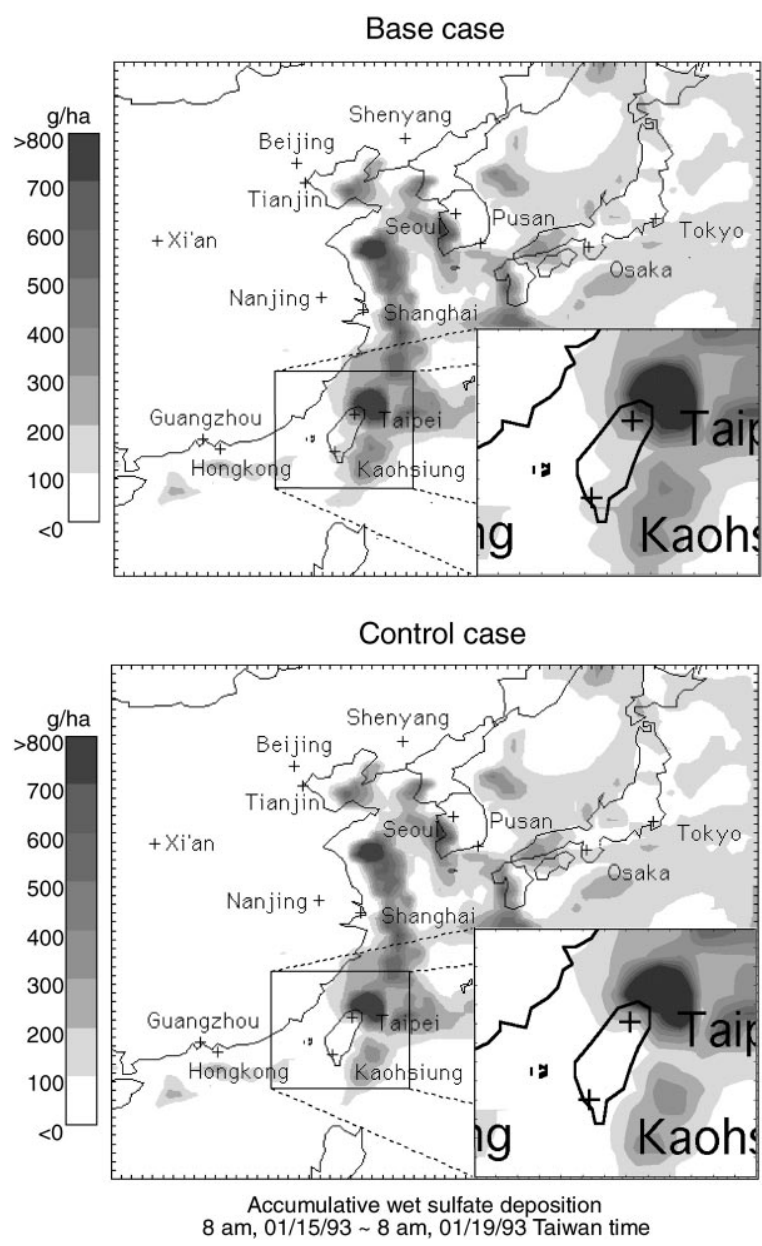

Fig. 8. Comparison of wet sulfate depositions between base case (upper) and control case (lower) during the northeasterly monsoon (I) episode.

sky of Japan and Taiwan. Thereafter, the $\mathrm{SO}_{x}$ concentration was diffused gradually.

\subsubsection{Comparison between base and control case}

In the northeasterly monsoon (I) episode, the accumulative wet and dry deposition distributions of sulfate for both base and control cases are shown in Figs. 8 and 9, respectively. Similar plots for nitrate are shown in Figs. 10 and 11. Major wet sulfate and nitrate depositions occurred in the northern part of Taiwan, East China Sea, western part of South Korea, and southern part of Japan during this episode. Since the spatial distribution in the base case is similar to that in the control case (w/o emission from Taiwan), the high wet sulfate deposition (400 $\mathrm{g} \mathrm{ha}^{-1}$ in Taipei) clearly indicates that Taiwan is strongly affected by long-range and transboundary transport in the northeasterly monsoon period. 

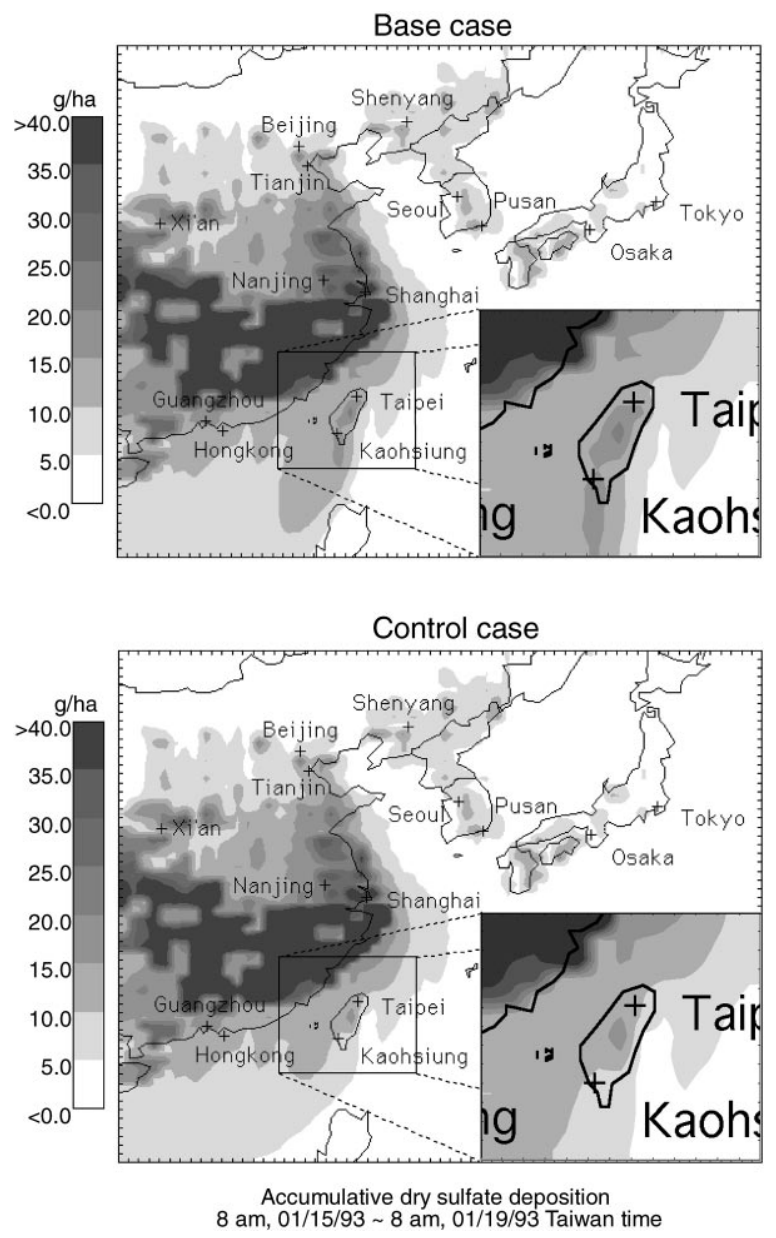

Fig. 9. Comparison of dry sulfate depositions between base case (upper) and control case (lower) during the northeasterly monsoon (I) episode.

In order to quantify the impact of LRT on Taiwan, the deposition amounts for all of the grids are summed for each substance containing sulfur and nitrogen. The summed values for the base and control cases are then used to calculate the impact ratio of LRT for Taiwan's acid deposition for each substance, as well as total sulfur and nitrogen compounds. For example, the wet sulfate impact ratio of $54 \%$ (Table 2 ) was obtained by dividing the value of the control case $\left(1.2 \times 10^{9} \mathrm{~g}\right)$ to that of the base case $\left(2.2 \times 10^{9} \mathrm{~g}\right)$. Data in Table 2 further indicate that LRT contributes about $39 \%$ of wet nitrate deposition, smaller than that for wet sulfate deposition $(54 \%)$.

Compared to wet deposition, the spatial distribution patterns of dry nitrate depositions are very different; the value in control case is clearly smaller than that in base case resulting in a lower impact ratio of $31 \%$. For comparison, the impact ratio for dry sulfate is $77 \%$ (Table 2). In addition to secondary pollutants (e.g., $40 \%$ in PAN),
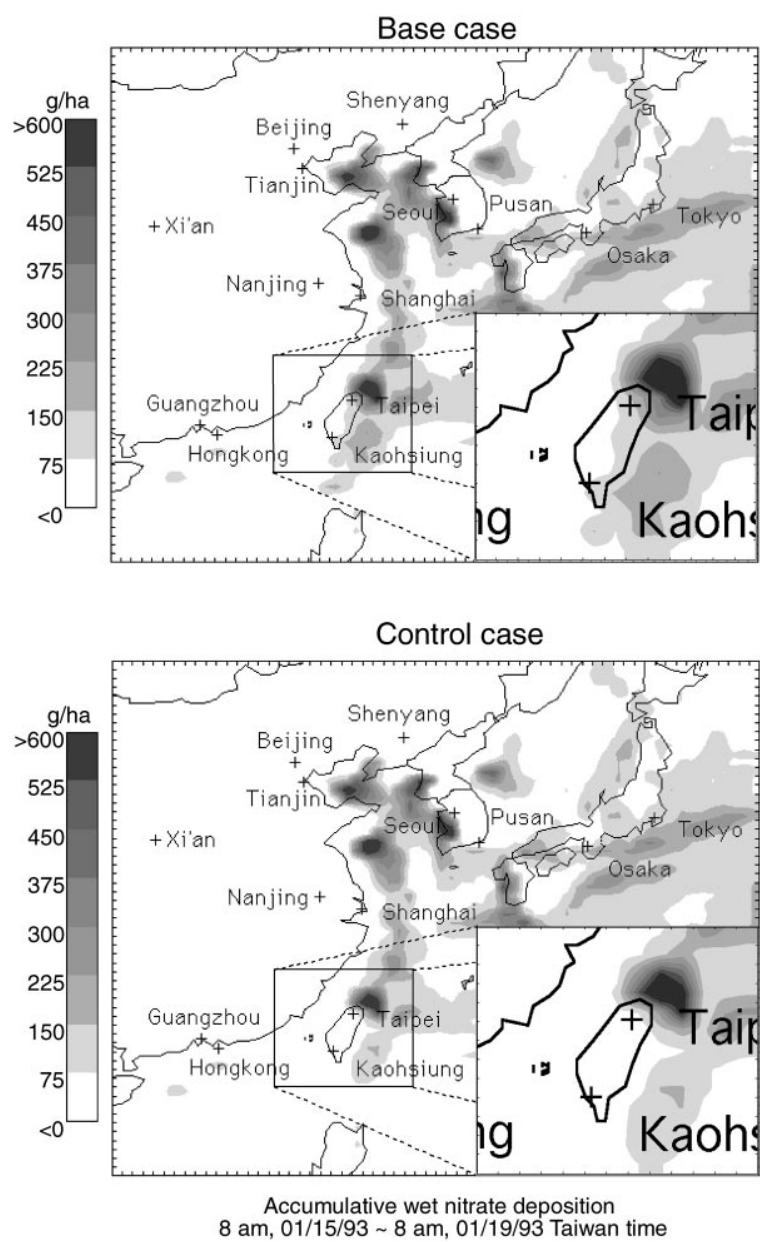

Fig. 10. Comparison of wet nitrate depositions between base case (upper) and control case (lower) during the northeasterly monsoon (I) episode.

dry $\mathrm{SO}_{2}$ deposition in Taiwan was also affected by LRT (impact ratio of $36 \%$ ), because of intensive $\mathrm{SO}_{x}$ emission in Shanghai area coupled with strong northeasterly wind to Taiwan. The dry $\mathrm{NO}_{2}$ deposition was, however, affected only slightly by about $4 \%$. In short, the total sulfur deposition including wet (sulfate) and dry $\left(\mathrm{SO}_{2}\right.$ and sulfate) depositions during the 4-d episode was $1.9 \times 10^{9} \mathrm{gm}$ (as S) of which $45 \%$ was contributed from LRT, while total nitrogen (wet nitrate/PAN and dry $\mathrm{NO}_{x} /$ nitrate) depositions is $6.6 \times 10^{8} \mathrm{~g}$ (as $\mathrm{N}$ ) of which $33 \%$ came from other countries.

\subsection{The effect of LRT in other episodes}

Because transport patterns show significant variations in different episodes, such as continental outflow in the winter episodes and onshore flow in the summer episodes, the LRT impact also presents significant 

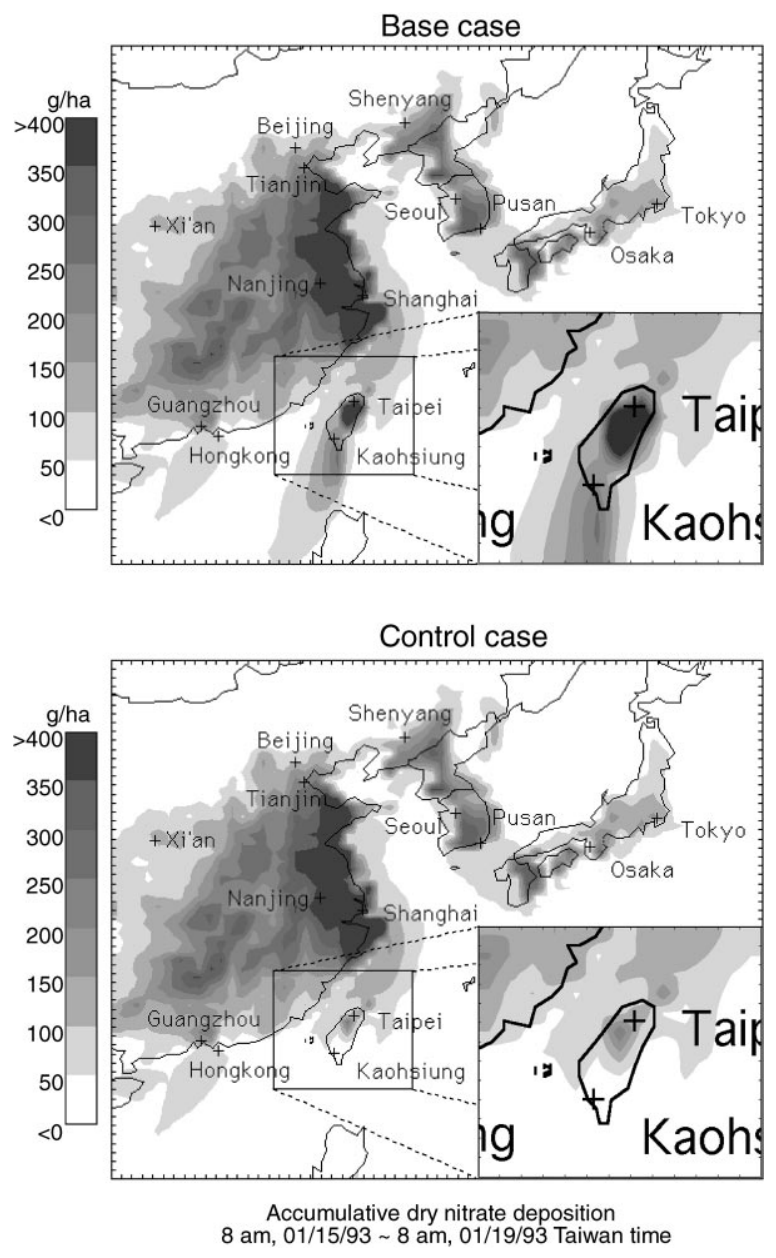

Fig. 11. Comparison of dry nitrate depositions between base case (upper) and control case (lower) during the northeasterly monsoon (I) episode.

differences. The ratios contributed by LRT for hydrogen ion deposition in Taiwan ranged from 30 to $56 \%$ (Table 2), with the lowest in episode 3 (Mei-Yu front) and the highest in both northeasterly monsoon episodes. For all other substances, the northeasterly monsoon (I) episode yields the most significant effect of LRT, with the northeasterly monsoon (II) episode next.

Since the impact ratios for both northeasterly monsoon episodes are relatively consistent, it is expected that different episodes of the same weather type could provide similar behavior. Thus, selected episodes in this study may reflect a representation of their corresponding weather types. The impact ratios of long range transport for total sulfur deposition in the six episodes vary from 9 to $45 \%$, with the lowest in the Autumn front, while those for total nitrogen depositions range from 6 to $33 \%$, with the lowest in the summer shower.

\subsection{Annual impact ratio and budget analysis}

The annual average of impact ratio of LRT is calculated as:

$D_{0}=\sum_{i} D_{i} \times W_{i}$

where $D_{0}$ is the annual average of impact ratio, $D_{i}$ the impact ratio for episode $i$, and $W_{i}$ the weighting factor for episode $i$. The weighting factor for each weather type is obtained from Lin and Chen (1997) based on the contribution ratio of the annual deposition amount. Briefly, the contribution of a particular parameter (wet sulfate or nitrate) for each episode to all 12 acid deposition monitoring stations was estimated $(5 \times 12$ matrix $)$, e.g., $16,20,26,36$, and $3 \%$, respectively, for the wet sulfate deposition at the Taipei station for the Monsoon, autumn front, summer shower, Mei-Yu front and Spring front. The sum of the weighting factors for five weather types should be equal to one. The average weighting value for each episode of all stations was then determined, and these values are shown in Table 3 . The annual average impact ratio of LRT for Taiwan is about $43 \%$ for hydrogen ion deposition, and 39 and $37 \%$ for wet sulfate and wet nitrogen deposition, respectively (Table 3). These ratios should be considered as conservative estimations, especially for sulfur, because all emission sources of foreign areas are treated as the area source and discharged at the ground level in the model as discussed previously. In addition, the LRT ratio obtained by comparing base and control case is based on the assumption that both precursors (e.g., $\mathrm{SO}_{x}$ and $\mathrm{NO}_{x}$ ) and oxidizers (e.g., $\mathrm{O}_{3}$ and $\mathrm{H}_{2} \mathrm{O}_{2}$ ) are transported in the same way. The precursors could be transported over a long distance, mixed with the oxdizers usually supplied by Taiwan, and then converted to acidic substances. Thus, the acidic substances could be underestimated around Taiwan in the control case due to underestimation of oxidizers supplied by Taiwan. Nevertheless, the LRT contributes the largest part in the summer shower for wet sulfate/nitrate and hydrogen ion depositions because its weighting factor is the highest (except for $[\mathrm{H}]$ ) among these pollutants. For comparison, the impact ratios of LRT for total sulfur deposition in Japan range from 15 to $83 \%$ (excluding volcanoes effect) at different locations (Arndt et al., 1998).

The sulfur and nitrogen budgets for Taiwan are presented in Tables 4 and 5 for all episodes. On the basis of 1993 Taiwan emission, about $3070 \mathrm{Mg}$ sulfur were emitted during each 4-d episode and $280 \mathrm{Gg}$ in the entire year in Taiwan; the corresponding values for nitrogen are $3400 \mathrm{Mg}$ and $310 \mathrm{Gg}$. The total sulfur depositions including wet and dry depositions range from 21 to $58 \%$ of total Taiwan sulfur emission for six episodes, while nitrogen depositions from 9 to $36 \%$. The annual average 
Table 3

Annual impact ratios (\%) of long-range transport for hydrogen ion, wet sulfate and wet nitrate depositions in Taiwan

Impact ratio $(\%) \quad$ Weighting factor $(\%)$

Annual impact ratio contribution $(\%)$

(1) Hydrogen ion deposition

Northeasterly monsoon ${ }^{\mathrm{a}}$

Autumn front

Summer shower

Mei-Yu front

Spring stationary front

$\begin{array}{lr}56 & 14 \\ 43 & 14 \\ 54 & 28 \\ 30 & 38 \\ 35 & 6\end{array}$

7.7

5.9

15

11

2.2

43

(2) Wet sulfate deposition

Northeasterly monsoon ${ }^{\mathrm{a}}$

Autumn front

Summer shower

Mei-Yu front

Spring stationary

front

Annual average of impact ratio

$\begin{array}{lcc}52 & 18 & 9.1 \\ 35 & 13 & 4.6 \\ 46 & 32 & 15 \\ 28 & 31 & 8.7 \\ 35 & 6 & 2.0\end{array}$

(3) Wet nitrate deposition

Northeasterly monsoon ${ }^{\mathrm{a}}$

Autumn front

$48+16$

$16 \quad 7.7$

Summer shower

Mei-Yu front 23

Spring stationary front $\quad 30$

Annual average of impact ratio
$13-5.1$

$33-16$

$31-7.0$

$6-1.8$

\footnotetext{
${ }^{\text {a }}$ Values in this row are the average of northeasterly monsoon (I) and (II).
}

would be in between these values, but it cannot be exactly estimated because the annual budget of dry deposition is difficult to calculate due to unavailable weighting factors in various weather conditions. The wet sulfur depositions range from 4 to $24 \%$ of total emission for various episodes and the annual average adjusted by the weighting factors in Table 4 is $13 \%$, whereas the wet nitrogen depositions vary from 2 to $7 \%$ with an annual average of $4 \%$. Clearly, most nitrogen is deposited in dry form rather than wet form. The average wet sulfur deposition contributed by LRT is about $5 \%$ of total Taiwan emission, while that contributed by native sources is around $8 \%$.

\section{Conclusions}

The major objective of this study was to explore the role of LRT for acid deposition in Taiwan using the TAQM. According to the results of this study, the annual average ratio impacted by long-range and transboundary transport in Taiwan is about $39 \%$ for wet sulfate depos- ition, and $37 \%$ for wet nitrate deposition. The effect of LRT is strongly dependent upon the weather type. Further, it has been demonstrated that there is a significant difference between primary (e.g., $\mathrm{SO}_{2}$ ) and secondary pollutants (e.g., sulfate) affected by the LRT. The results indicate that the efforts for achieving local precursor reduction might not be adequate enough to improve Taiwan's acid deposition. Consequently, a sensible way to improve current acid deposition problems is to develop regional cooperation among the countries and areas in East Asia to reduce all of their emissions simultaneously and separately.

\section{Acknowledgements}

This study was supported by the funds from Taiwan EPA as part of the Acid Deposition Effect Project. We are grateful to Dr. Hajime Akimoto for providing Asia emission data. Special thanks are to CTCI for providing Taiwan emission data. 


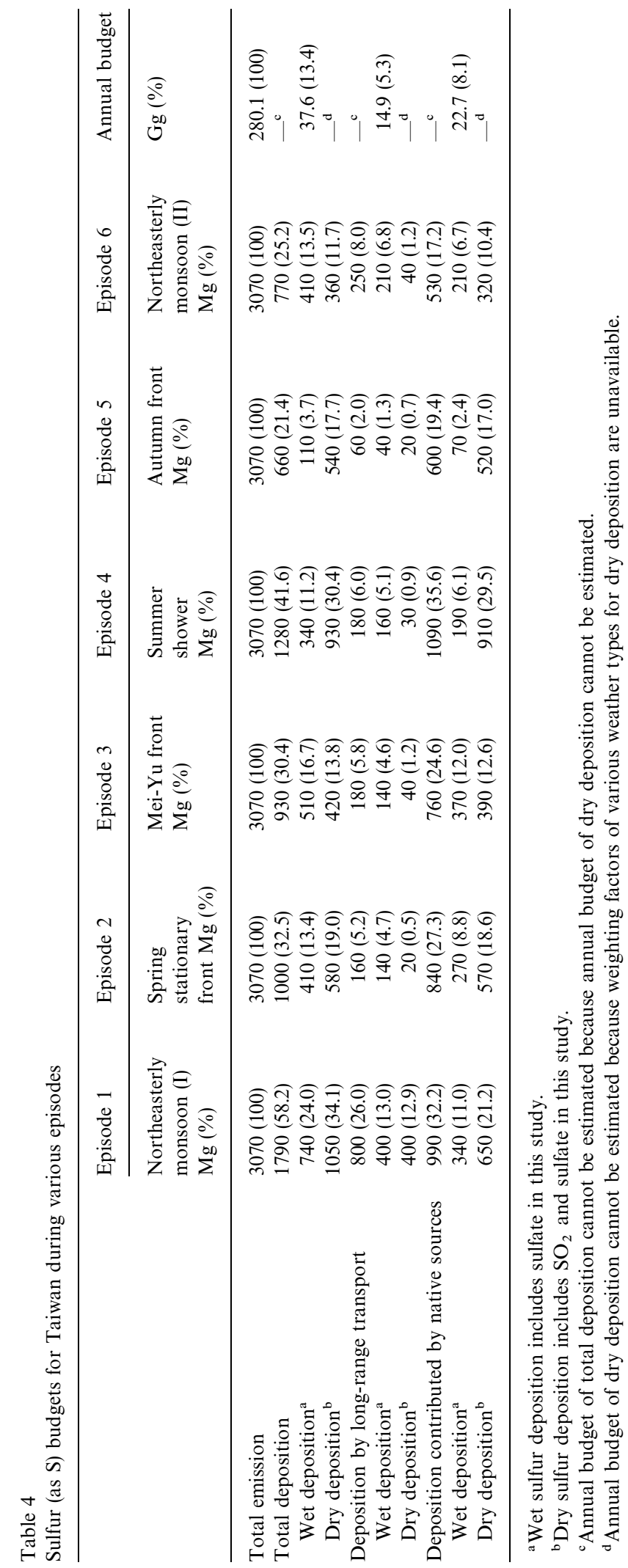




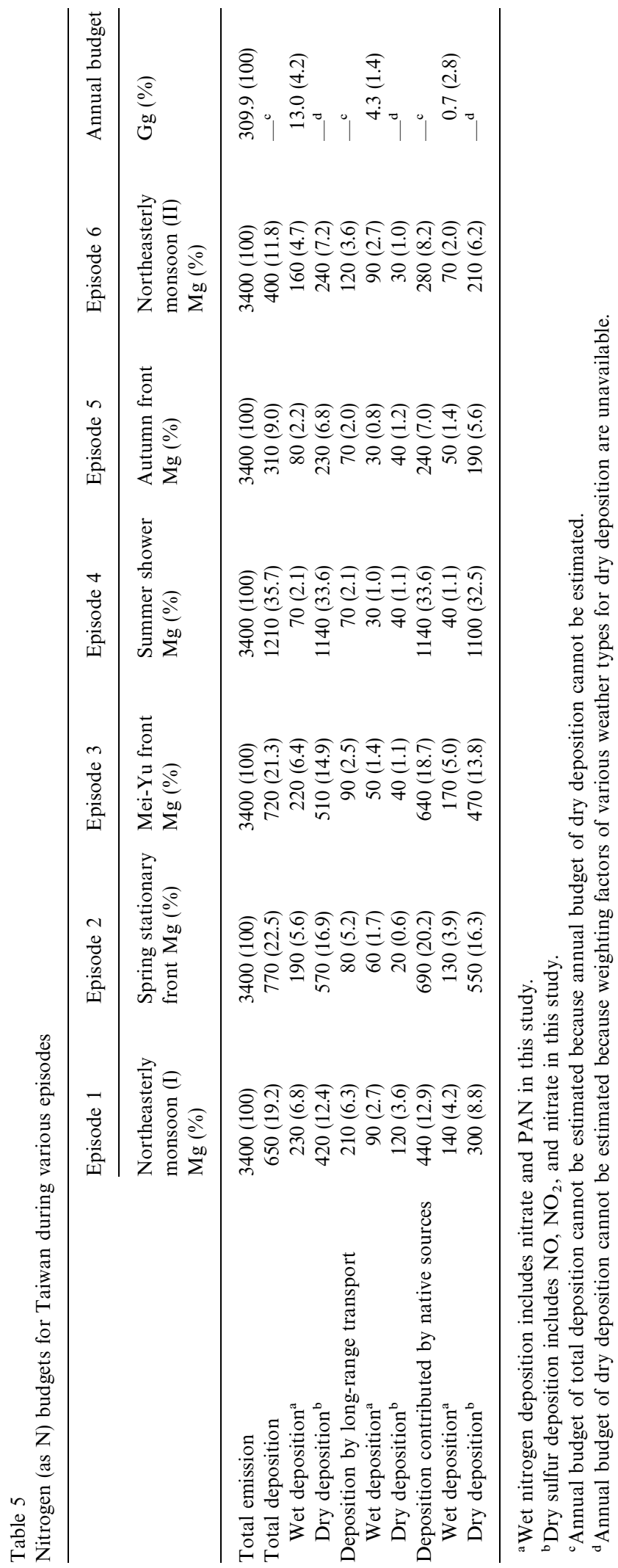




\section{References}

Akimoto, H., Narita, H., 1994. Distribution of $\mathrm{SO}_{2}, \mathrm{NO}_{x}$ and $\mathrm{CO}_{2}$ emissions from fuel combustion and industrial activities in Asia with $1 \times 1$ degree resolution. Atmospheric Environment 18, 213-225.

Arndt, R.L., Carmichael, G.R., Roorda, J.M., 1998. Seasonal source-receptor relationships in Asia. Atmospheric Environment 32, 1397-1406.

Bott, A., 1989a. A positive definite advection scheme obtained by nonlinear renormalization of the advective fluxes. Monthly Weather Review 117, 1006-1015.

Bott, A., 1989b. Reply. Monthly Weather Review 117, 2633-2636.

Chang, J.S., Brost, R.A., Isaksen, I.S.A., Madronich, S., Middleton, P., Stockwell, W.R., Walcek, C.J., 1987. A three-dimensional Eulerian acid deposition model, physical concepts and formulation. Journal of Geophysical Research 92, 14681-14700.

Chang, J.S. (principal author), 1990. The regional acid deposition model and engineering model. Acidic Deposition: State of Science and Technology Report 4, National Acid Precipitation and Assessment Program, Washington, DC. 130pp.

Chang, K.H., Jeng, F.T., 1995. Simulation of regional air quality of Taiwan. Proceedings International Conference Regional Photochemical Measurement and Modeling Studies, San Diego, CA, Results and Status of Modeling, Vol. 2, pp.706-726.

CTCI, 1995. Improvement/maintenance program of air quality for each county in Taiwan - II. Final Report for Taiwan EPA, China Technological Consulting Inc. (in Chinese).

Dudhia, J., 1993. A nonhydrostatic version of the Penn StateNCAR mesoscale model: validation tests and simulation of an Atlantic cyclone and cold front. Monthly Weather Review 121, 1493-1513.

Gear, C.W., 1971. Numerical Initial Value Problems in Ordinary Differential Equations. Prentice-Hall, Englewood Cliffs, NJ.

Grell, G.A., Dudhia, J., Stauffer, D.R., 1993. A description of the fifth-generation Penn State/NCAR mesoscale model (MM5).
NCAR Technical Note, NCAR/TN-398 + STR. Boulder, CO. $117 \mathrm{pp}$.

Hayami, H., Ichikawa, Y., 1995. Development of hybrid LRT model to estimate sulfur deposition in Japan. Water, Air, Soil Pollution 85, 2015-2020.

Huang, M., Wang, Z., He, D., Xu, H., Zhou, L., 1995. Modeling studies on sulfur deposition and transport in East Asia. Water, Air, Soil pollution 85, 1921-1926.

Ichikawa, Y., Fujita, S., 1995. An analysis of wet deposition of sulfate using a trajectory model for East Asia. Water, Air, Soil Pollution 85, 1927-1932.

Kitada, T.P., Lee, C.S., Ueda, H., 1992. Numerical modeling of long-range transport of acidic species in association with meso- $\beta$-convective-clouds across the Japan Sea resulting in acid snow over coastal Japan - I: Model description and qualitative verifications. Atmospheric Environment 27A, 1061-1076.

Lin, L.H., Chen, J.S., 1997. A study on the source-receptor relationship of acid deposition: air stream trajectory analysis and precipitation system effect. Final Report for Taiwan EPA. EPA-86-FA44-09-47, 244pp. (in Chinese).

Madronich, S., 1987. Photodissociation in the atmosphere: 1. actinic flux and the effects of ground reflections and clouds. Journal of Geophysical Research 92, 9740-9752.

Pleim, J.E., Chang, J.S., 1992. A non-local closure model for vertical mixing in the convective boundary layer. Atmospheric Environment 26A, 965-981.

Stockwell, W.R., Middleton, P., Chang, J.S., 1990. The second generation regional acid deposition model chemical mechanism for regional air quality modeling. Journal of Geophysical Research, D10, 95, 16343-16367.

Walcek, C.J., Taylor, G.R., 1986. A theoretical method for computing vertical distributions of acidity and sulfate production within growing cumulus clouds. Journal of Atmospheric Sciences 43, 339-355.

Wu, C.C., Kou, W.S., Yang, C.S., 1991. A study on long-range transport of air pollutants over East Asia. Proc. 8th Conf. Air Pollut. Control and Technol., Taipei, Taiwan, pp. 277-287. (in Chinese). 